\title{
Prevalence of Theileriosis in Buffaloes during Rainy Season in and Around Patna, Bihar
}

\author{
Shashi Kala ${ }^{1 *}$, Bhawesh Gopal Deo ${ }^{2}$ and Nikee Kumari ${ }^{1}$ \\ ${ }^{1}$ J.A.R.O., Institute of Animal Health and Production, Bihar, Patna \\ ${ }^{2}$ R.O., Institute of Animal Health and Production, Bihar, Patna \\ *Corresponding author
}

\begin{tabular}{|l|}
\hline Ke y w o r d s \\
Theileriosis, \\
Prevalence, Rainy \\
$\begin{array}{l}\text { Season, Blood } \\
\text { smear, Buffaloes }\end{array}$ \\
\hline Article Info \\
\hline $\begin{array}{l}\text { Accepted: } \\
\text { 26 March } 2018 \\
\text { Available Online: } \\
\text { 10 April } 2018\end{array}$ \\
\hline
\end{tabular}

A total of 75 suspected blood samples from buffaloes were screened by using Giemsa staining technique during the rainy season. The present study was conducted for a period of 6 months from June 17 to November 17. The microscopic examination of stained blood smears were performed and presence of intraerythrocytic piroplasms in different shapes like round, oval, signet ring, pear, comma, rod or bacilli indicating the prevalence of theileriosis in buffaloes in and around Patna, Bihar. The smears were examined minutely and at least 10 randomly selected microscopic fields were studied. Out of 75 suspected cases of buffaloes, $7(9.33 \%)$ were found positive for theileriosis. The prevalence of the disease was highest $(11.11 \%)$ during post monsoon (October-November) followed by August-September $(9.75 \%)$ and June-July (6.25\%), might be due to abundance of vector during post monsoon. Previously the incidence and prevalence of theileriosis in buffaloes has been reported from different parts of India by various workers in several years. However, the status of Theileria infection has not yet been reported in buffaloes in Bihar. So the study was designed to record the prevalence of theileriosis in Buffaloes in and around Patna, Bihar.

\section{Introduction}

Theileriosis is tick borne haemoprotozoan disease caused by different species of genus Theileria coming under family Theileridae. Theileria is obligate intracellular parasite infecting both domestic as well as wild bovines and small ruminants and is transmitted by Ixodid ticks having complicated life cycle (Khan et al., 2017). The hot and humid climate is favourable for the development and survival of potential vectors and is a constant source of infection to susceptible animals (Velusamy et al., 2014; Maharana et al., 2016). The climate of tropical and subtropical regions favours incidence, growth and multiplication of ticks predisposing the animals to parasitic ailments and consequently declining dairy production (Sajid, 2007; Khan et al., 2017).

Theileriosis is considered as one of the major constraints in livestock health and production throughout the world. Young exotic and crossbred cattle are highly susceptible. Indian breeds of cattle (Zebu) are comparatively 
resistant to the infection. Buffaloes are also infected but symptoms are mild. Haemoprotozoan disease especially Theileriosis imposes considerable restraints on buffalo production and causes both population and economic losses (Durani et al., 2006).

There are different species of Theileria, among which Theileria annulata and Theileria parva are considered as most pathogenic species. Theileria parva is probably originally a parasite of Afircan buffalo (Syncerus caffer) that has become adapted to cattle. African Cape buffalo (Syncerus caffer) is the wildlife reservoir of multiple species within the apicomplexan protozoan genus Theileria, including Theileria parva which cause East coast fever in cattle (Bishop et al., 2015).

Buffalo-derived Theileria parva can be considered to be a group of Theileria Parva strains which are adapted to tick transmission within the African buffalo population, including the red dwarf buffalo (Syncerus caffer nanus) of Angola. The African buffalo carries many indistinguishable strains and species of Theileria and the epidemiology is complicated and poorly understood (Allsopp et al., 1993).

The diagnosis of haemoprotozoan infections largely depends on various laboratory-based diagnostic methods as the clinical manifestations are inconspicuous and nonspecific (Maharana et al., 2016). The confirmatory diagnosis depends on microscopic examination of Giemsa stained thin blood smears (Aktas et al., 2006; Qayyum et al., 2010). Giemsa staining technique is frequently used for detection of parasite as it is comparatively inexpensive.

Previously the incidence and prevalence of theileriosis in buffaloes has been reported from different parts of India by various workers in several years, Indore (Waskel and
Gaur, 2015) and Gujarat (Vahora et al., 2015 and Maharana et al., 2016). However, the status of Theileria infection in buffaloes has not yet been reported in Bihar which shares $6.96 \%$ buffalo population of India (Livestock Census, 2012). Therefore, the present investigation was conducted to study the prevalence of theileriosis in buffaloes in and around Patna, Bihar.

\section{Materials and Methods}

\section{Data collection}

A total of 75 blood samples of buffaloes suspected for haemoprotozoan disease were received at parasitology section of Institute of Animal Health and Production, Bihar, Patna during the period of 6 months from June 2017 to November 2017. Approximately $2 \mathrm{ml}$ of blood samples were received in a vial containing anticoagulant (EDTA vial). Generally, cases were referred by field veterinarians. Majority of the cases were manifesting clinical symptoms of increased body temperature, anorexia, nasal discharge, lacrimation and history of tick infestation.

\section{Smear preparation and microscopical examination}

Thin blood smears were prepared, air dried, fixed with methanol for 3-5 minutes, and stained with Giemsa stain (1:10 ratio) for 3040 minutes and then extra stain was poured off and removed by washing with tap water. The stained smears were examined under oil immersion lens (100X). The parasites were identified according to the characters described by Soulsby (1982). The smears were examined carefully and even presence of single piroplasm considered as positive for Theileria (Kohli et al., 2014). On the basis of number of piroplasm these were graded as mild or severe (Fig. 2). At least 10 randomly chosen oil immersion fields were studied. 


\section{Results and Discussion}

To study the prevalence of theileriosis in Buffaloes during rainy season, the investigation was conducted for a period of 6 months from June 2017 to November 2017. A total of 75 blood smears of buffaloes were analysed by using Giemsa staining technique (Fig. 2), out of which 7(9.33\%) were found positive for theileriosis (Table 1). Mostly the blood samples of suspected cases were studied, though the rate of infections was low. This might be due to various factors like low sensitivity of microscope, time of blood collection, site of blood collection etc., which reduce the chance of parasites detection in blood smears. The study was conducted in and around Patna, Bihar for a period of 6 months and analysed bi-monthly prevalence of theileriosis in buffaloes during rainy season.
Bihar is located in eastern region of India. In Bihar monsoon season commences soon after mid-June and continues till the end of September. September-November retreated as post monsoon season due to invasion of tropical cyclones originating in the Bay of Bengal at about $12^{0} \mathrm{~N}$ latitude in Bihar.

From Table 1 (Fig. 1), Bi-monthly study revealed that the incidence of the disease was highest during October-November $(11.11 \%)$ followed by August-September (9.75\%) and June-July $(6.25 \%)$. The prevalence of the theileriosis in buffaloes was maximum during post monsoon season (11.11\%), might be due to increase in tick population during the season. The abundance of tick was reported in the month of July (Sajid et al., 2007), whereas Hyalomma spp. of tick is most abundant in June (Durrani et al., 2008).

Fig.1 Graphical representation of Bi-monthly distribution of theileriosis in buffaloes. Fig.2 Microscopic field (100X) showing piroplasm

Fig.1

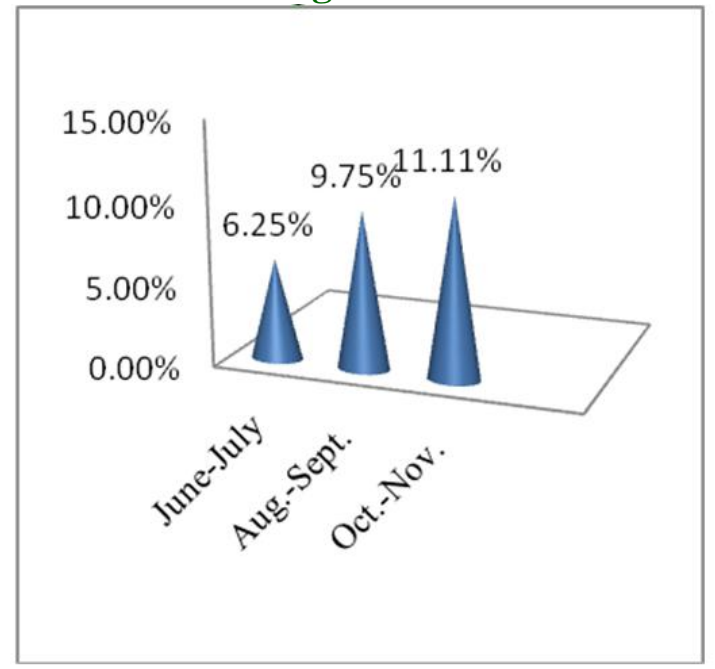

Fig.2

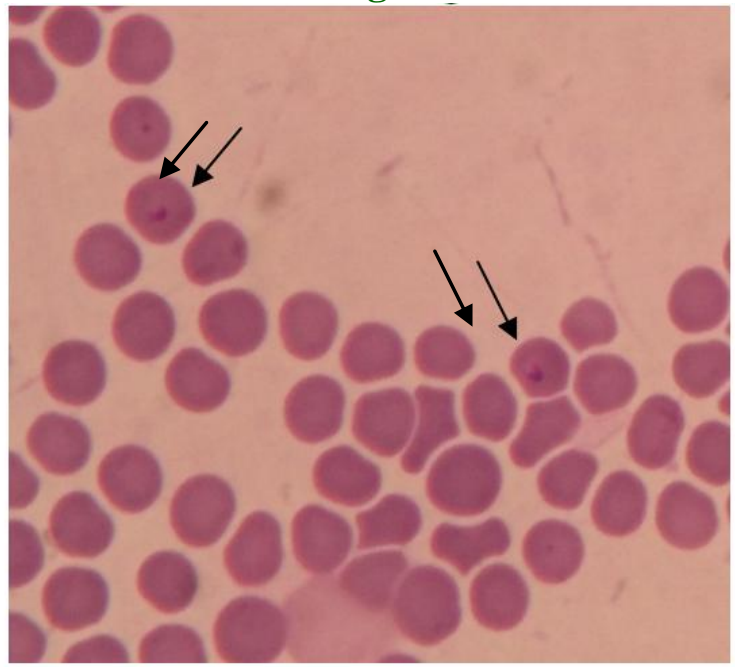

Table.1 Bi-monthly distribution of theileriosis in buffaloes

\begin{tabular}{|c|c|c|}
\hline Month & No of positive cases & Total no. cases examined \\
\hline June-July & $1(6.25)$ & 16 \\
\hline August-September & $4(9.75)$ & 41 \\
\hline October-November & $2(11.11)$ & 18 \\
\hline Total & $7(9.33)$ & 75 \\
\hline
\end{tabular}

Figure in parenthesis indicates percentage 
Ananda et al., (2009) reported, most of the animals suffered during monsoon months might be due to more number of ticks in monsoon which were developed during summer months.

The overall prevalence of the disease in monsoon season was $9.33 \%$. Our study was in close agreement with Maharana et al., 2016, who recorded $7.27 \%$ prevalence of theileriosis in buffaloes during monsoon season. In a similar study Waskel and Gaur (2015), reported $47.91 \%$ incidence of theileriosis in buffaloes from eight different regions of Indore District during rainy season. According to Durani et al., (2006), the overall incidence of infected cases of theileriosis in buffaloes were estimated to be $17.8 \%$ and the highest incidence was in the month of August (20.5\%) followed by September (17.5\%) and July (15.5\%) from Jia Bagga Jhadoo and Ghang Sharif of union council Jia Bagga District, Lahore. However, Vahora et al., (2012) reported $37 \%$ and $17 \%$ positive cases of haemoprotozoan infection in crossbred cattle and buffaloes respectively in Kaira and Anand District of Gujarat and recorded higher incidence of theileriosis during monsoon season. In another study Kundave et al., (2014) recorded, $72.52 \%$ (out of 91 samples 66 were positive) cattle and $32 \%$ (out of 25 samples 8 were positive) buffalo were positive for Theileria annulata by adopting PCR technique.

Latif et al., (2002) reported, the infection rate with Theileria parasites in ticks collected from buffalo-grazed pasture was high which produced fatal theileriosis in susceptible cattle and similarly adult Rhipicephalus appendiculatus ticks artificially fed on nymphs on the buffaloes produced fatal infections in susceptible cattle. He et al., (2012) investigated, the presence and prevalence of tick-borne haemoparasites in water buffalo from the Hubei Province, South China using the reverse line blot (RLB) hybridisation assay and polygenetic analysis of the parasite 18S rRNA gene.

It was concluded that, in Bihar Theileriosis is not only confined to cattle but also prevalent in buffaloes though unlike cattle symptoms are mild and is a constant source of infection for susceptible animals. In order to reduce the incidence and prevalence of the disease there is a need for further investigation by using molecular diagnostic technique like PCR and proper control measure should be adopted.

\section{References}

Aktas, M., Altay, K. and Dumanli, N., 2006. A molecular survey of bovine Theileria parasites among apparently healthy cattle and with a note on the distribution of ticks in estern Turkey. Vet. Parasitol. 138:179185.

Allsopp, B.A., Baylis, H.A., Allsopp, M.T.E.P., Cavalier-Smith, T., Bishop, B.R., Carrington, D.M., Sohanpal, B., Spooner, P., 1993. Discrimination between six species of Theileria using oligonucleotide probes which detect small subunit ribosomal RNA sequences. Parasitology 107, 157-165.

Ananda, K.J., D'Souza, P.E., Puttalakshmamma, G.C. 2009. Prevalence of Haemoprotozoan diseases in crossbred cattle in Banglore north. Vet. World, 2(1): $15-16$

Bishop, R.P., Hemmink, J.D., Morrision, W.I., Weir, W., Toye, P.G., Sitt, T., Spooner, P.R., Musoke, A.J., Skilton, R.A., Odongo, D.O. 2015. The African buffalo parasites Theileria. Sp. (buffalo) can infect and immortalize cattle leukocytes and encodes divergent orthologues of Theileria parva antigen genes. Int.J. for Parasitology: Parasites and Wildlife.4: 333-342.

Durrani, A.Z., Kamal, N. and Khan, M.S. 2006. Incidence of theileriosis and estimation of packed cell volume, total erythrocyte count and haemoglobin in buffaloes. J.Anim.Pl.Sci.1 6(3-4):85-88.

Durrani, A.Z., Shakoori, A.R., Kamal, N. 2008. Bionomics of Hyalomma ticks in three districts of Punjab, Pakistan. J. Anim. Plant Sci., 18(1): 20-23. 
He L, Feng HH, Zhang WJ, Zhang QL, Fang R, Wang LX, Tu P, Zhou YQ, Zhao JL, Oosthuizen MC. 2012. Occurrence of Theileria and Babesia species in water buffalo (Bubalus babalis, Linnaeus, 1758) in Hubei province, South China. Vet Parasitol. May 25; 186(3-4) 490-6.

Khan, A., Ashfaq, K., Din, I., Haq, R., Jamil, M., Ullah, B., Ullah, S., Rehman, H., Ullah, F., 2017. Bovine theileriosis: prevalence, estimation of haematological profile and chemotherapy in cattle in Dera Ismail Khan, Khyber Pakhtunkhwa Province, Pakistan. Ameri. Sci. Res. J. for Eng. Tech. and Sci. (ASRJETS), 32(1): 817

Kohli, S., Atheya, U.K., Thapliyal, A. 2014. Prevalence of theileriosis in cross-bred cattle: its detection through blood smear examination and polymerase chain reaction in Dehradun district, Uttarakhand, India. Veter. World, 7(3): 168-171.

Kundave, V.R., Patel, A.K., Patel, P.V., Hasnani, J.J. and Joshi, C.G., 2014. Qualitative and quantitative assessment of Theileria annulata in cattle and buffaloes Polymerase Chain Reaction. Tropical Biomedicine 31(4):728-735.

Latif AA, Hove T, Kanhai GK, Masaka S, 2002. Buffalo-associated Theileria parva: the risk to cattle of buffalo translocation into the Highveld of Zimbabwe. Ann NY Acad Sci. Oct; 969:275-9.

Livestock Census (2012). Ministry of Animal Husbandry, Dairying and Fisheries, Ministry of Agriculture, Govt. of India.

Maharana, B.R., Kumar, B., Prasad, A., Patbandhan, T.K., Sudhakar, N.R., Joseph, J.P. and Patel, B.R., 2016. Prevalence and assessment of risk factors for haemoprotozoan infections in cattle and buffaloes of South -West Gujarat, India. Indian J. Anim. Res., 50(5); 733739.

Maharana, B.R., Tewari, A.K., Saravanan, B.C., Sudhakar, N.R., 2016. Important hemoprotozoan diseases of livestock: Challenges in current diagnostics and therapeutics: An update, Veterinary World, 9(5): 487-495.

Qayyum, A., Farooq, U., Samad, H.A., Chauhdry, H.R. 2010. Prevalence, clinicotherapeutic and prophylactic studies on theileriosis in district Sahiwal (Pakistan). J. Anim. Plant Sci., 20(4): 266-270.

Sajid, M.S. 2007. Epidemiology, acaricidal resistance of tick population infesting domestic ruminants, Ph.D. Thesis, University of Agriculture, Faisalabad, Pakistan.

Soulsby, E.J.L. 1982. Helminths, arthropods and protozoan of domesticated animals, $7^{\text {th }}$ edn., Bailiere Tindall and Cassell Ltd., London.

Vahora, S.P., Patel, J.V., Parel, B.B., Patel, S.B., Umale, R.H. 2012. Seasonal incidence of haemoprotozoan disease in crossbred cattle and buffalo in Kaira and Anand district of Gujarat, India. Veter World, 5(4): 223-225.

Velusamy, R., Rani, N., Ponnudurai, G., Harikrishnan, T.J., Anna, T., Arunachalam, K., Senthilvel, K. and Anbarasi, P. (2014) Influence of season, age and breed on prevalence of haemoprotozoan diseases in cattle of Tamil Nadu, India, Veterinary World 7(8): 574-578.

Waskel, S. and Gaur, U.2015. Incidence of theileriosis in cattle and buffaloes during rainy season. Euro. J. Exp. Bio., 5(8):7173.

\section{How to cite this article:}

Shashi Kala, Bhawesh Gopal Deo and Nikee Kumari. 2018. Prevalence of Theileriosis in Buffaloes during Rainy Season in and Around Patna, Bihar. Int.J.Curr.Microbiol.App.Sci. 7(04): 2762-2766. doi: https://doi.org/10.20546/ijcmas.2018.704.315 